\title{
Recomendações em cirurgias bucomaxilofaciais de urgência e emergência em tempos de COVID-19
}

Recommendations in urgent and emergency oral and maxillofacial surgeries in times of COVID-19

Recomendaciones en cirugías orales y maxilofaciales urgentes y de emergencia en tiempos de COVID-19

Layla Louise de Amorim ROCHA ${ }^{1}$

Matheus Francisco Barros RODRIGUES ${ }^{1}$

Rimsky Coelho Lopes da ROCHA ${ }^{2}$

Rodrigo da Franca ACIOLY $\mathbf{A}^{2}$

Daniel do Carmo CARVALHO ${ }^{3}$

Dennis Dinelly de SOUZA ${ }^{3}$

Cristofe Coelho Lopes da ROCHA ${ }^{4}$

${ }^{I}$ Curso de Odontologia, Faculdade Cathedral, 69307-053 Boa Vista - RR, Brasil

${ }^{2}$ Centro de Pesquisas Odontológicas, São Leopoldo Mandic, Boa Vista 69305-455, Brasil

${ }^{3}$ Departamento de Cirurgia e Traumatologia Bucomaxilofacial, Hospital Geral de Roraima, 69305-455 Boa Vista - RR, Brasil

${ }^{4}$ Departamento infraestrutura, Instituto Federal, 69303-340 Boa Vista - RR, Brasil

\section{Resumo}

Embora as rotas de transmissão da COVID-19 ainda não estejam totalmente identificadas, a transmissão homem-a-homem já é uma realidade em muitos países. Este trabalho tem por objetivo reunir recomendações dos órgãos de saúde e de estudos em artigos científicos relacionadas a condutas especiais do cirurgião bucomaxilofacial no período perioperatório de urgência e emergência. A justificativa é a possibilidade de infecção cruzada por meio da inalação de partículas produzidas durante os procedimentos cirúrgicos. A abordagem desse trabalho está relacionada à rota de transmissão e a possibilidade de contaminação cruzada da COVID-19 por meio de gotículas de salivas transformadas em aerossóis. Considera-se que a adoção de condutas especiais no período periorperatório por parte do cirurgião bucomaxilofacial pode representar auxílio quanto a prevenção de transmissão do vírus tanto em relação aos profissionais quanto aos pacientes.

Descritores: Infecções por Coronavírus; Assistência Perioperatória; Aerossóis; Transmissão de Doença Infecciosa do Paciente para o Profissional.

\section{Abstract}

Although the transmission routes for COVID-19 are not yet fully identified, the human-to-human transmission is already a reality in many countries. This work aims to gather recommendations from health agencies and studies in scientific articles related to special conducts of oral and maxillofacial surgeons in the perioperative period of urgency and emergency. The justification is the possibility of cross-infection through the inhalation of particles produced during surgical procedures. The approach of this work is related to the transmission route and the possibility of cross contamination of COVID-19 by means of saliva droplets transformed into aerosols. It is considered that the adoption of special procedures in the periorperative period by the buccomaxillofacial surgeon may represent an aid as well as the prevention of virus transmission both in relation to professionals and patients.

Descriptors: Coronavirus Infections; Perioperative Care; Aerosols; Infectious Disease Transmission, Patient-to-Professional.

\section{Resumen}

Aunque las rutas de transmisión de COVID-19 aún no están completamente identificadas, la transmisión de persona a persona ya es una realidad en muchos países. Este trabajo tiene como objetivo reunir recomendaciones de agencias de salud y estudios en artículos científicos relacionados con conductas especiales de cirujanos orales y maxilofaciales en el período perioperatorio de urgencia y emergencia. La justificación es la posibilidad de infección cruzada a través de la inhalación de partículas producidas durante los procedimientos quirúrgicos. El enfoque de este trabajo está relacionado con la ruta de transmisión y la posibilidad de contaminación cruzada de COVID-19 por medio de gotas de saliva transformadas en aerosoles. Se considera que la adopción de procedimientos especiales en el período periorperatorio por parte del cirujano buccomaxilofacial puede representar una ayuda, así como la prevención de la transmisión del virus, tanto en relación con los profesionales como con los pacientes.

Descriptores: infecciones por Coronavirus; Atención Perioperativa; Aerosoles; Transmisión de Enfermedad Infecciosa de Paciente a Profesional

\section{INTRODUÇÃO}

Um novo coronavírus foi identificado como agente etiológico de um surto de pneumonia na China com transmissão de pessoa a pessoa e posterior internacionalização dos $\operatorname{casos}^{1}$. O vírus foi inicialmente denominado 2019-nCoV e em seguida foi oficialmente definido como SARS-CoV-2, um dos três tipos de coronavírus zoonótico que originou a síndrome respiratória aguda grave (severe acute respiratory syndrome - SARS), seguida da síndrome respiratória do oriente médio (middle east respiratory syndrome-coronavirus - MERS) ${ }^{2}$.

Embora as rotas de transmissão da COVID-19 ainda não estejam totalmente identificadas, a transmissão homem-a-homem já é uma realidade em muitos países ${ }^{3,4}$. Acredita-se que a transmissão interpessoal ocorra por meio de gotículas respiratórias expelidas durante fala, tosse, espirro ou contato direto com pessoas infectadas em forma de aerossois ${ }^{4}$. Recentemente, foi identificada a presença de coronavírus na saliva de pacientes infectados ${ }^{3-6}$.

Alguns estudos baseados na cavidade bucal de pacientes contaminados identificaram grande quantidade de RNA SARS-CoV-2 na saliva, sugerindo a possibilidade de transmissão de coronavírus por meio de gotículas bucais ${ }^{6}$.

O Ministério da Saúde do Brasil, expressa os dados epidemiológicos do vírus realizando uma comparação dos índices de internações de 2019 à 2020. O Gráfico 1 demonstra que nos dias 1 e 2 ocorrem discretamente o início das internações. Todavia, um crescimento maior chega a atingir 9.920 pessoas internadas no dia 13.

Este trabalho tem por objetivo reunir recomendações dos órgãos de saúde e de es- tudos científicos relacionadas à condutas especiais do cirurgião bucomaxilofacial no período perioperatório de urgência e emergência. A justificativa é a possibilidade de infecção cruzada por meio da 
inalação de partículas produzidas durante os procedimentos cirúrgicos ${ }^{3,7,8}$. Considera-se que a adoção de condutas especiais no período periorperatório por parte do cirurgião bucomaxilofacial pode representar um auxílio aumentando sua segurança no procedimento.

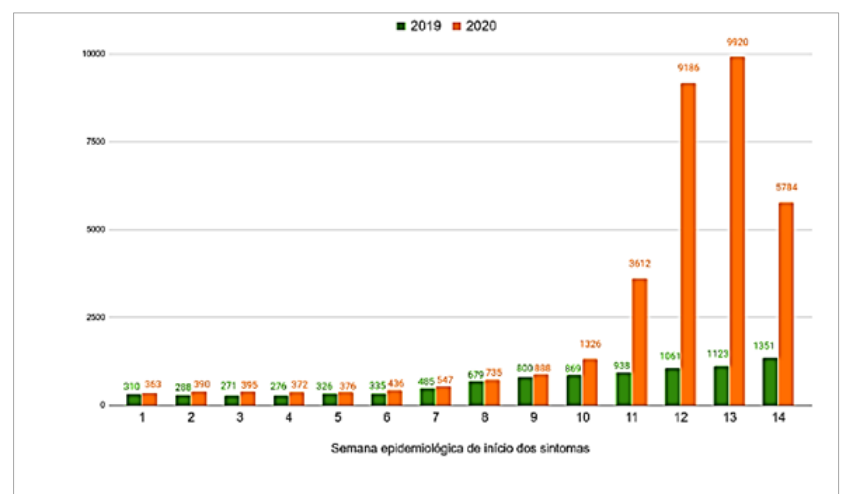

Gráfico 1: Comparação entre 2019 e 2020 nos índices de hospitalização por síndrome respiratória aguda grave na semana epidemiológica do início dos sintomas da COVID-19

\section{MATERIAL E MÉTODO}

Foram levantadas recomendações do Colégio Brasileiro de Cirurgia e Traumatologia Bucomaxilofacial, Ministério da Saúde do Brasil, Organização Mundial da Saúde - OMS, Agência Nacional de Vigilância Sanitária - ANVISA, Organização Americana Crâniomaxilofacial - AO CMF, Associação Americana de Cirurgiões Orais e Maxilofaciais - AAOMS, Conselho Federal de Odontologia do Brasil (CFO) e Associação de Medicina Intensiva Brasileira (AMIB). Adicionalmente, foi realizada a análise de estudos científicos da quantidade de RNA do vírus encontrado na saliva e casos clínicos de pacientes que passaram por procedimentos cirúrgicos durante $o$ surto da COVID-19 obtidos no boletim emitido pelo Hospital Israelita Albert Einsten, ambos consubstanciaram a contribuição deste trabalho.

A abordagem dessa pesquisa está relacionada a rota de transmissão e a possibilidade de contaminação cruzada da COVID-19 por meio de gotículas de salivas em ambientes hospitalares durante o período perioperatório em cirurgias bucomaxilofaciais de urgência e emergência.

\section{RESULTADOS E DISCUSSÃO}

\section{- Rotas de transmissão e risco de contaminação cruzada}

As partículas podem seguir diferentes rotas de transmissão durante um procedimento cirúrgico, as gotículas de saliva alcançam menores distâncias e caem rapidamente no chão em função da força gravitacional, exigindo maior proximidade entre os indivíduos. Todavia, partículas geradas por aerosol podem percorrer maiores distâncias ${ }^{4}$.

Foram realizados estudos que se basearam no RNA viral extraído da saliva e sobrenadante da lavagem da garganta e depois submetido a um RTPCR quantitativo em tempo real ${ }^{9}$. A quantidade de RNA SARS-CoV na lavagem da garganta foi $9,58 \mathrm{x}$ 102 a 5,93 x 106 cópias por mL (mediana 3,56 x 103 cópias / mL). O RNA de SARS-CoV também foi detectado na saliva de todas as 14 amostras disponíveis. No estudo foi observado grandes quantidades de RNA do vírus na lavagem da garganta. Esta constatação apoia a possibilidade de que o SARS-CoV possa ser transmitido por meio de gotículas orais.

Um estudo baseado em 12 pacientes com a COVID-19 na cidade de Hong Kong demonstrou em amostras de salivas a presença de coronavírus em 11 dos pacientes $(91,7 \%)$, atestando a presença do RNA viral também na saliva ${ }^{5}$. O uso de uma peça de mão de alta velocidade ou instrumentos ultrassônicos em contato com fluidos corporais como saliva ou sangue faz com que ocorra a produção de aerossóis no ambiente $^{7}$. A inalação dessas partículas de aerossóis produzidas em pacientes com a COVID-19 representam alto risco de infeção cruzada entre cirurgiões dentista e pacientes ${ }^{3,4,7,8}$

Foi detectado RNA da SARS-CoV no plasma de pacientes com SARS, mesmo sendo uma doença respiratória. O primeiro relatório publicado em 10 de abril de 2003 indicou que existiam concentrações extremamente baixas de RNA viral no plasma de um paciente com SARS durante a fase aguda da doença, 9 dias após o início dos sintomas. Os pesquisadores detectaram o RNA de SARS-CoV usando um teste de PCR aninhado estabelecido internamente e a carga viral foi de 190 cópias $/ \mathrm{mL}$, realizada após a ultracentrifugação de $2 \mathrm{~mL}$ de plasma $^{10}$.

Durante um procedimento bucomaxilofacial hospitalar, várias superfícies podem abrigar partículas contaminadas, visto que o vírus pode sobreviver em superfícies por até nove dias ${ }^{11}$. Caso não haja um processo eficaz de descontaminação, a transmissibilidade do vírus torna-se um agravante durante todo o perioperatório, representando uma fonte de exposição para os profissionais de saúde ${ }^{12}$.

- Cuidados perioperatórios em cirurgias bucomaxilofaciais

Fraturas maxilofaciais estão entre as causas mais comuns de ocorrências em um setor de emergência bucomaxilofacial ${ }^{13}$. Nesses casos, o tratamento imediato é indispensável e o cirurgião deve atentar aos cuidados perioperatórios.

O Hospital Israelita Albert Einsten elaborou um boletim ${ }^{1}$ baseado em 4 casos clínicos de pacientes que passaram por procedimentos cirúrgicos durante o surto da COVID-19 e apresentaram complicações pós-operatórias. Dentre eles, três desenvolveram

${ }^{1}$ Boletim Hospital Israelita Albert Eisten. Disponível em: https://www.einstein.br/Pages/Home.aspx 
febre pós- operatória e complicações pulmonares após operações eletivas sem intercorrências. $\mathrm{O}$ diagnóstico e tratamento corretos no pós-operatório foram desafiadores e dois dos pacientes foram a óbito. Há diversas opções para diagnósticos diferenciais em pacientes com sinto- mas pulmonares pós-operatórios. No entanto, durante o atual surto progressivo é necessário suspeitar da COVID-19 para fazer um diagnóstico correto e tomar as ações corretas a fim de tratar o paciente e impedir a propagação do vírus.

A COVID-19 pode complicar o curso perioperatório com desafio diagnóstico e uma alta taxa de mortalidade potencial, sobretudo quando paciente é assintomático. Considera- se que cuidados especiais durante as cirurgias bucomaxilofaciais podem representar um auxílio para equacionar riscos de transmissão cruzada, sobretudo em pacientes assintomáticos.

\section{- Condutas especiais em procedimentos perioperatórios em cirurgias bucomaxilofaciais de urgência e emergência}

Diante do quadro epidemiológico do coronavírus, como medida de precaução, deve-se considerar os pacientes assintomáticos como suspeitos de infecção, a menos que tenham dois testes COVID-19 negativos separados por pelo menos 24 horas em função da possibilidade de resultados falsonegativos $^{14}$. Os pacientes que testam positivo para COVID-19 ou apresentam sintomas de infecções agudas, patologias ativas ou lesões orais e maxilofaciais, devem receber cuidados em hospitais ou clínicas de referência ${ }^{14}$.

É fundamental que os procedimentos de urgência e emergência sejam realizados de maneira a evitar a disseminação do vírus. A Tabela 1 foi elaborada para auxiliar em situações práticas de cirurgias bucomaxilofaciais, sua finalidade é demonstrar as condutas especiais mais indicadas a serem seguida pelo cirurgião durante o período perioperatorio em conformidade com as recomendações dos órgãos de saúde.

A análise da Tabela 1 permite observar os procedimentos e as condutas adotadas relacionadas de acordo com cada situação. No período préoperatório faz-se necessário realizar uma análise da real necessidade de realizar o procedimento, uma vez que orienta- se que procedimentos não funcionais sejam prorrogados com o intuito de evitar riscos desnecessários de transmissão do vírus. Mesmo não havendo sinais e sintomas do coronavírus no paciente, devem ser utilizados toda a paramentação cirúrgica, a fim de evitar a transmissão do vírus como também de outros microorganismos ${ }^{14}$.

Os processos que favorecem a aerossolização de escarro em pessoas infectadas e potencialmente infectadas no ambiente perioperatório representam uma possível fonte de exposição para os profissionais de saúde. O contato direto com gotículas respiratórias durante o manejo das vias aéreas, para os anestesistas e intensivistas, é o período que repre- senta o maior risco de exposição, principalmente durante a intubação e extubação ${ }^{12}$. É recomendado que a equipe de cirurgia se mantenha em espera, fora da sala por pelo menos 20 minutos, aguardando que o ambiente se mostre livre de patógenos após a intubação do paciente $^{14}$.

Tabela 1: Recomendações de condutas e procedimentos especiais no perioperatório em CTBMF frente a transmissão da COVID-19.

\begin{tabular}{|c|c|c|}
\hline Período & Procedimentos & Condutas adotadas \\
\hline Pré-operatório & $\begin{array}{l}\text { Observar a possibilidade de alta } \\
\text { precoce e discutir a real necessidade } \\
\text { do procedimento cirúrgico }{ }^{15}\end{array}$ & $\begin{array}{c}\text { Prorrogar procedimentos não } \\
\text { funcionais, priorizando os casos } \\
\text { com potencial de infecção e os } \\
\text { que comprometam as vias aéreas } \\
\end{array}$ \\
\hline UTI ou leitos & $\begin{array}{l}\text { Avaliar a necessidade de uso de leito } \\
\text { de UTI e leito em pós-operatorio }\end{array}$ & $\begin{array}{c}\text { Evitar acompanhantes em } \\
\text { enfermaria. Número limitado de } \\
\text { auxiliares e funcionários. } \\
\text { Adequados EPI e treinamento } \\
\text { para a equipe. }\end{array}$ \\
\hline $\begin{array}{l}\text { Paramentação } \\
\text { cirúrgica }\end{array}$ & $\begin{array}{l}\text { Precauções com procedimentos com } \\
\text { aerossóis, por meio do uso de } \\
\text { máscara de proteção respiratória } \\
\text { (respirador particulado) com eficácia } \\
\text { mínima, na filtração, de } 95 \% \text { de } \\
\text { partículas de até o,3 } \mu \text { (tipo N95, } \\
\text { N99, N100, PFF2 ou PFF3). } \\
\end{array}$ & $\begin{array}{c}\text { Uso dos EPIs como: máscara } \\
\text { cirúrgica, luvas, avental não es- } \\
\text { téril e óculos de proteção. A } \\
\text { máscara cirúrgica deve ser } \\
\text { utilizada para a proteção } \\
\text { individual, observando a } \\
\text { colocação adequada }{ }^{14}\end{array}$ \\
\hline $\begin{array}{l}\text { Momentos antes } \\
\text { de iniciar o ato } \\
\text { operatorio }\end{array}$ & $\begin{array}{l}\text { Baseado na troca de ar da sala de } \\
\text { cirurgia e nas experiências na China } \\
\text { e Itália, entre } 14 \text { e } 20 \text { minutos o ar } \\
\text { esta livre de patógenos após a } \\
\text { intubação do paciente }{ }^{14}\end{array}$ & $\begin{array}{c}\text { Equipe aguardar } 20 \text { minutos fora } \\
\text { da sala cirúrgica após a intubação } \\
\text { do paciente }{ }^{14}\end{array}$ \\
\hline Acesso Cirúrgico & $\begin{array}{l}\text { Quando possível optar por } \\
\text { procedimentos cirúrgicos fechados, } \\
\text { caso não seja possível dar } \\
\text { preferência ao acesso extraoral pela } \\
\text { possibilidade de diminuição do } \\
\text { aerossol bucal'14,16 }\end{array}$ & Utilizar o Bisturi frio ${ }^{14,16}$ \\
\hline Osteotomia & $\begin{array}{c}\text { Os procedimentos que exigem } \\
\text { desgastes ósseos devem ser } \\
\text { realizados sem ou com limitada } \\
\text { irrigação } 0^{14} \\
\end{array}$ & Fazer uso de cinzéis e martelo ${ }^{14}$ \\
\hline $\begin{array}{c}\text { Bloqueio e Fixação } \\
\text { das fraturas }\end{array}$ & $\begin{array}{c}\text { A redução e fixação das fraturas } \\
\text { devem ser realizadas de forma } \\
\text { menos traumáticas possível } \\
\text { minimizando o uso de perfuradores } \\
\text { que produzam aerossóis }\end{array}$ & $\begin{array}{l}\text { Utilizar técnicas menos invasivas } \\
\text { como o uso de bloqueio } \\
\text { maxilomandibular com parafusos } \\
\text { IMF autoperfurantes. Se a fixação } \\
\text { interna FOR estritamente } \\
\text { necessária para a estabilidade da } \\
\text { redução, priorizar os parafusos } \\
\text { autoperfurantes }\end{array}$ \\
\hline Irrigação & $\begin{array}{c}\text { Somente deve ser realizado em casos } \\
\text { realmente necessários, sendo } \\
\text { limitada } \\
\end{array}$ & Convencional \\
\hline Aspiração & $\begin{array}{c}\text { Deve-se realizar aspiração de saliva, } \\
\text { no entanto deve-se evitar repetidas } \\
\text { aspirações }{ }^{16}\end{array}$ & Convencional \\
\hline
\end{tabular}

No acesso cirúrgico, foi realizada abordagem quanto ao melhor acesso a ser empregado considerando o cenário atual. É indicado aos cirurgiões que utilizem o bisturi frio e realizem o procedimento fechado. Quando possível, sempre optar pelo acesso extraoral, visto que a cavidade bucal apresenta fluidos como a saliva que possui grande carga viral ${ }^{16}$.

Durante a osteotomia são utilizados instrumentos com sistema de refrigeração, o qual gera aerossóis e pode levar a contaminação cruzada entre o paciente e o cirurgião. Portanto, recomenda-se o uso dos instrumentais sem irrigação ou com irrigação limitada e sempre que possível substituir o uso de cinzel. Em casos de fraturas é recomendado que a redução e fixação sejam feitas de forma menos traumática possível e minimizar o uso de perfuradores que produzam aerossóis ${ }^{14}$. A irrigação e aspiração devem ser realizadas somente quando necessário, evitando a geração de aerossóis ${ }^{14}$. Quanto a 
aspiração, deve ser evitada repetitivas aspirações, também como forma de prevenção ${ }^{16}$.

\section{CONSIDERAÇÕES FINAIS}

É fundamental para o cirurgião
bucomaxilofacial adotar medidas preventivas, além de redobrar a atenção no perioperatório de pacientes submetidos em situação de urgência e emergência ao serviço de saúde. A intenção de seguir recomendações é diminuir a transmissibilidade do vírus, evitando sua disseminação. A etapa cirúrgica requer maior atenção por ser o período de maior contato do cirurgião com fluidos corporais do paciente. Em alguns casos, pacientes acometidos pela COVID-19 não demonstram sintomatologia, todavia as condutas especiais não se restringem apenas à pacientes confirmados ou sob suspeita e sim a todos os submetidos ao serviço de saúde no período crítico da COVID-19.

\section{REFERÊNCIAS}

1. Shoji H, Fonseca EKUN, Teles GBDS, et al. Structured thoracic computed tomography report for COVID-19 pandemic. Einstein (Sao Paulo). 2020;18:eED5720.

2. Wu Z, McGoogan JM. Characteristics of and Important Lessons From the Coronavirus Disease 2019 (COVID-19) Outbreak in China: Summary of a Report of 72314 Cases From the Chinese Center for Disease Control and Prevention. JAMA. 2020;323(13):1239-42.

3. Sabino-Silva R, Jardim ACG, Siqueira WL. Coronavirus COVID-19 impacts to dentistry and potential salivary diagnosis. Clin Oral Investig. 2020;24(4):1619-21.

4. Rodrigues MFB, Rocha LLDA, Acioly RDF, Souza DDD, Carvalho DDC, Rocha RCLD, Rocha CCLD. Special precautions in oral and maxillofacial surgeries regarding COVID-19 transmission. Preprints 2020, 2020050135 (doi: 10.20944/preprints202005.0135.v1).

5. To KKW, Tsang OTY, Leung WS, Tam AR, Wu TC, Lung DC et al. Temporal profiles of viral load in posterior oropharyngeal saliva samples and serum antibody responses during infection by SARS-CoV2: an observational cohort study. Lancet Infect Dis. 2020;20(5):565-74.

6. Ather A, Patel B, Ruparel NB, Diogenes A, Hargreaves KM. Coronavirus Disease 19 (COVID19): Implications for Clinical Dental Care. J Endod. 2020;46(5):584-95.

7. Meng L, Hua F, Bian Z. Coronavirus Disease 2019 (COVID-19): Emerging and Future Challenges for Dental and Oral Medicine. J Dent Res. 2020;99(5):481-87.

8. Ge ZY, Yang LM, Xia JJ, Fu XH, Zhang YZ. Possible aerosol transmission of COVID-19 and special precautions in dentistry. J Zhejiang Univ Sci B. 2020;21(5):361-68.
9. Wang WK, Chen SY, Liu IJ, Chen YC, Chen HL, Yang CF et al. Detection of SARS-associated coronavirus in throat wash and saliva in early diagnosis. Emerg Infect Dis. 2004;10(7):1213-19.

10. Chang L, Yan Y, Wang L. Coronavirus Disease 2019: Coronaviruses and Blood Safety. Transfus Med Rev. 2020;34(2):75-80.

11. Spagnuolo G, De Vito D, Rengo S, Tatullo M. COVID-19 Outbreak: An Overview on Dentistry. Int J Environ Res Public Health. 2020;17(6):2094.

12.Zucco L, Levy N, Ketchandji D, Aziz M, Ramachandran SK. Considerações perioperatórias para o novo coronavírus 2019 (COVID-19). Rochester: ASPF; 2020.

13. Abosadegh MM, Saddki N, Al-Tayar B, Rahman SA. Epidemiology of maxillofacial fractures at a teaching hospital in Malaysia: a retrospective study. BioMed Res Int. 2019: 9024763.

14. Colégio Brasileiro de Cirurgia e Traumatologia Bucomaxilofacial (CTBMF). COVID-19 - Guia de Práticas em CTBMF. Disponível em: https://www.bucomaxilo.org.br/site/noticiasdetalhes. php?cod=344\&amp;q=COVID19\%2B\%20\%2BGuia $\% 2 \mathrm{Bde} \% 2 \mathrm{BPr} \% \mathrm{C} 3 \% \mathrm{~A} 1$ ticas$\% 2 \mathrm{Bem} \% 2 \mathrm{BCTBMF} \&$ amp;bsc=ativar. Acesso em: 07 de abr. de 2020.

15. American Association of Oral and Maxillofacial Surgeons (AAOMS). Member Alert: COVID-19 Guidance for OMS Practices. Disponível em: https://www.aaoms.org/news/member-alert-covid19-guidance-for-oms-practices. Acesso em: 10 de fev. de 2020.

16. AOCMF International Task Force Recommendations on Best Practices for Maxillofacial Procedures during COVID-19 Pandemic. Disponível em: https://aocmf3.aofoundation.org//media/project/aocmf/aocmf/files/covid19/ao_cmf_covid-19_task_force_guidelines.pdf. Acesso em: 10 de fev. de 2020.

\section{CONFLITO DE INTERESSES}

Os autores declaram não haver conflitos de interesse.

\section{AUTOR PARA CORRESPONDÊNCIA}

\author{
Layla Louise de Amorim Rocha \\ Curso de Odontologia, Faculdade Cathedral \\ 69307-053 Boa Vista - RR, Brasil \\ e-mail: matheusfbr18@gmail.com
}

